\title{
CORRELATION BETWEEN IFN- $\gamma$ LEVELS, CHEST RADIOGRAPHY AND THE POSITIVITY OF SMEAR SPUTUM IN NEW TB CASES AT THE DR.SOETOMO HOSPITAL
}

\author{
Yessy Puspitasari, Jusak Nugraha
}

Department of Clinical Pathology, Faculty of Medicine, Airlangga University/Dr. Soetomo Hospital, Surabaya, Indonesia. E-mail: redblomen@gmail.com

\section{ABSTRACT}

Tuberculosis is an infectious disease attacking lungs, triggering damage, and pulmonary dysfunction. Host cytokine responses will influence tuberculosis manifestations. The main host immune response is cellular immunity, and Delayed-Type Hypersensitivity (DTH). IFN- $\gamma$ produced by Th- 1 , is a major cytokine acting to eliminate TB bacteria through macrophage activation. Chest radiography has an important value for the diagnosis of TB, especially in negative sputum smears. Radiological manifestations depend on several factors including host prior to TB exposure, age, and immune status. Sputum smear is also important in diagnosing, and assessing response to treatment of adult pulmonary TB. A cross-sectional study, comprising a total of 36 new pulmonary TB cases at the Dr.Soetomo Hospital who met the inclusion, and exclusion criteria, were establish. Plasma IFN- $\gamma$ was examined by ELISA. Chest radiography was divided into three categories based on the National Tuberculosis Association of USA. Sputum smear data were taken from medical records. There were significant correlations between IFN $-\gamma$ plasma levels with chest radiography $(r=0.365 ; \rho=0.029)$, IFN $-\gamma$ with positive sputum smear $(r=0.447 ; \rho=0.006)$, positive sputum smear with chest radiography $(r=0.674$; $\rho=0.001$ ) IFN- $\gamma$ plasma levels could reflect lesion area on chest radiography, and sputum smear positivity. IFN- $\gamma$ plasma levels, chest radigraphy, and sputum positivity may reflect a Th-1immune response, so the more severe level of diseases, an immune response Th-1 become more activated.

Key words: IFN- $\gamma$, new TB cases, Mycobacterium tuberculosis, cellular immunity, delayed type hypersensitivity

\section{INTRODUCTION}

Tuberculosis infections are a major health problem in Indonesia. Indonesia still rank as forth in the world based on the WHO report, after India, China, and South Africa. Estimation for TB prevalence is 730,000 cases every year, 460,000 new cases per year. The death rate is approximately 67,000 per year. ${ }^{1}$

After it inhaled, and deposited in distal alveoli, M.tuberculosis is ingested by alveolar macrophages and neutrophils, monocytes derived macrophages, and dendritic cells. Whereas virulent strain called M.tuberculosis could survive within the resting macrophage, specific cytokins has an important role to control M.tuberculosis, and mediated by Th1, such as IFN $-\gamma$, tumor necrosis factor, and vitamin D. ${ }^{2}$ Th2 cytokines are typically involved in humoral immunity mediated by antibody. Th2 has limited protection againts intracellular mycobacterial infection. ${ }^{3}$

Tuberculosis is an example of an infection with an intracelluler bacterium in which protective immunity and pathologic hypersensitive coexist, and the lession are mainly caused by the host response. More then $90 \%$ infected patients remain asymptomatic, but bacteria survive in lung, and can be reactivated. By 6-8 weeks after infection, regional lymhph nodes are involved, and $\mathrm{CD}^{+} 4 \mathrm{~T}$ cells are activated. These $\mathrm{T}$ cell produce IFN- $\gamma$ which activate macrophage, and also enhance their ability to kill phagocytosed bacilli. ${ }^{4}$

The importance of IFN- $\gamma$ in response to M.tuberculosis has been widely investigated in experimental models and in humans. Knockout mice for IL-12, IFN- $\gamma$ or T-bet are highly susceptible to TB. Furthermore, result of from other studies demonstrated that peripheral blood mononuclear cells from patients with active disease secreted lower IFN- $\gamma$ in vitro, both in unstimulated culture or after stimulated mitogen or mycobacterial antigen. ${ }^{5}$ Despite the important role of IFN- $\gamma$ to control M.tuberculosis, some studies have shown that IFN- $\gamma$ is insuficient to prevent 
active disease. It has been shown that patients whose T cells produce higher amounts of IFN- $\gamma$ are more likely to progress in to active disease than patients with weaker responses. ${ }^{5}$ A study stated that although variation of IFN- $x$ production among various subjects, levels of IFN- $\gamma$ are increased, and help in differenting diagnosis between pulmonary $\mathrm{TB}$, and latent tuberculosis infections (using MtbHag-10k in the PBMC). ${ }^{6}$

In cases negative smear and even positive smear, radiographic changes are helpful in disease diagnosis. Although some chest X-ray findings, including nodular or patchy infiltration in the posterior parts of the superior lobes or anterior segments of the inferior lobes particularly in bilateral involvement, and associated with cavity, are not specific for pulmonary tuberculosis, clinical manifestations and epidemiologic findings are very diagnostic. ${ }^{7}$ The clinical course of tuberculosis, and appropriate radiological patterns depend on the interaction between organisms, and host responses. ${ }^{8}$ Radiological manifestations of pulmonary tuberculosis depend on several factors from the host, including previous exposure to TB, age, and immunity status. ${ }^{9}$ Host immune response has an important role to determine the result of interaction between host, and pathogens.

Sputum culture should be performed to confirm the diagnosis of pulmonary tuberculosis because Mycobacterium culture requires expensive tools, and time. Acid-fast staining that is simple, and easy has been widely used for diagnosing $\mathrm{TB}$, and treatment evaluation. ${ }^{10}$ Acid fast staining microscopically from patients sputum who have pulmonary infiltrates, and cavities are consistent with tuberculosis. ${ }^{11}$

This research was conducted to assess the correlation between cellular immune response, especially IFN- $\gamma$ expression in new TB cases with chest radiography, and the positivity of sputum.

\section{METHODS}

A cross-sectional study was conducted consisting 36 adult new TB patients at the Dr.Soetomo Hospital that fulfilled requirement. IFN- $\gamma$ plasma levels were examined by ucytechELISA.12 Chest radiography taken from medical records was divided into three categories based on the National Association of USA 1961. Acid fast bacilli staining data were taken from the medical records..

\section{RESULT AND DISCUSSION}

Following characteristics data from 36 new TB cases samples during the period January 2015 until March 2015 are presented in Table 1.

Table 1. Characteristics of research subjects

\begin{tabular}{lc}
\hline Cases & 36 \\
\hline Gender : Males/females & $26(72.2) / 10$ \\
& $(27.8)$ \\
Mean age & $35.33 \pm 14.36$ \\
Minimal age & 15 \\
Maximal & 69 \\
Chest radiography: & \\
Minimal lesion & $17(47.2)$ \\
Moderate lesion & $9(25)$ \\
Extensive lesion & $10(27.8)$ \\
BTA sputum & \\
Negative & $15(41.7)$ \\
+1 & $8(22.2)$ \\
+2 & $8(22.2)$ \\
+3 & $5(13.9)$ \\
\end{tabular}

As many as 36 patients with new TB cases fulfilled the inclusion, and exclusion criteria. There were twenty six males (72.7\%), and 10 females (27.8\%) according to sex. Based on the age, new pulmonary TB cases were obtained with a mean \pm SD of $35.33 \pm$ 14.36 years. A total of 36 patients who had minimal lesions on chest ragiography were $17(47.2 \%)$, total patients with moderate lesions were 9 patients (25\%), extensive lesions were 10 patients (27.8\%). (Table 1 ).

Table 2 could explain that the average plasma level of IFN- $\gamma$ in pulmonary TB patients with minimal lesions was $4.5 \pm 4.02 \mathrm{pg} / \mathrm{mL}$, the mean plasma level of IFN- $\gamma$ in pulmonary TB patients with moderate lesion was $14.16 \pm 13.51 \mathrm{pg} / \mathrm{mL}$ whereas, the mean plasma levels of IFN- $\gamma$ in patients with pulmonary tuberculosis with extensive lesions was $13.31 \pm 13.31$. A similar study was conducted by Hussein et al., ${ }^{14}$ on 54 active TB patients, and 37 healthy controls measuring IFN- $\gamma$ levels in the blood, showed there was a significant difference in IFN- $\gamma$ levels in active TB patients compared to 19 healthy controls. ${ }^{14}$ Moderate lesions had higher IFN- $\gamma$ level than extensive lesions which could not be explained completely but there was a significant correlation between IFN- $\gamma$, and chest radiography. Classification of chest radiography into small, moderate, and extensive lesion could be differed by the experts. 
Table 2. Mean plasma levels of IFN-r in patients with pulmonary TB new cases

\begin{tabular}{|c|c|c|c|c|}
\hline \multirow{2}{*}{$\begin{array}{l}\text { Overview chest radiog- } \\
\text { raphy }\end{array}$} & \multirow{2}{*}{$\begin{array}{c}\text { Mean } \pm \text { SD } \\
\text { IFN- } \gamma \\
(\mathrm{pg} / \mathrm{mL}) \\
\end{array}$} & \multicolumn{2}{|c|}{$95 \% \mathrm{Cl}$ for mean } & \multirow[t]{2}{*}{ Spearman test } \\
\hline & & Lower bound & Upper bound & \\
\hline Minimal lesion & $4.5 \pm 4.02$ & 2.43 & 6.57 & \\
\hline Moderate lesion & $14.16 \pm 13.51$ & 3.78 & 24.55 & \\
\hline Extensive lesion & $13.31 \pm 13.31$ & 3.78 & 22.83 & \\
\hline IFN $-\gamma$ VS chest radiography & & & & $\begin{array}{l}r=0.365 \\
(p=0.029)\end{array}$ \\
\hline
\end{tabular}

Table 3. Mean IFN- $x$ levels in new pulmonary Tb patients based on the positivity of Acid Fast Bacilli Staining

\begin{tabular}{|c|c|c|c|c|}
\hline \multirow[t]{2}{*}{ AFB Positivity } & \multirow{2}{*}{ 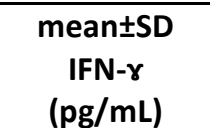 } & \multicolumn{2}{|c|}{$95 \% \mathrm{Cl}$ for mean } & \multirow[t]{2}{*}{ Spearman test } \\
\hline & & Lower bound & Upper bound & \\
\hline Negative & $3.65 \pm 2.49$ & 2.27 & 5.04 & \\
\hline+1 & $12.31 \pm 10.71$ & 3.35 & 21.27 & \\
\hline+2 & $8.96 \pm 6.95$ & 3.15 & 14.78 & \\
\hline+3 & $22.4 \pm 18.99$ & -1.18 & 45.99 & \\
\hline $\begin{array}{l}\text { IFN- } \gamma \text { VS sputum } \\
\text { positivity }\end{array}$ & & & & $\begin{array}{c}r=0.447 \\
(p=0.006)\end{array}$ \\
\hline
\end{tabular}

The highest level of IFN- $\gamma$ in pulmonary TB patients could be found at positive of sputum positivity +3 , and the lowest level of IFN- $y$ could be found at positive of sputum positivity +1 (Table 3 ). There was a significant correlation between IFN- $\gamma$, and sputum positivity.

A strong, and significant correlation was found in the relationship between chest radiograpy and sputum positivity ( $r=0674 ; p=0.0001)$. Another study showed a correlation between Chest radiography, and sputum smear such as Ebrahimzadeh et al., ${ }^{7}$ although radiographic findings were not diagnostic in pulmonary tuberculosis, they were helpful if the assessment associated with the view of clinical manifestations, and sputum smears. ${ }^{7}$ Saidu et al., ${ }^{15}$ showed that patchy or streaking opacities, and cavity lesions were the commonest radiographic features in their study. Chest radiography remained an useful instrument to diagnosis, and subsequent by in the management of pulmonary TB. ${ }^{15}$ It could be explained that the clinical course of tuberculosis, and appropriate radiological patterns depended on the interaction between organisms, and host responses. ${ }^{8}$ Radiological manifestations of pulmonary tuberculosis depended on several factors from the host including previous exposure to TB, age, and immunity status. ${ }^{9}$ Host immune response had an important role to determine result of interaction between host, and pathogen.
Table 4. Chest radiography vs sputum positivity

\begin{tabular}{llll}
\hline Correlation & \multicolumn{1}{c}{$\begin{array}{c}\text { Coeficient } \\
\text { correlation } \\
\text { Spearman's rho }\end{array}$} & P-value & Result \\
\hline Chest & 0.674 & 0.0001 & significant \\
radiography & & (significant & \\
VS Sputum & & if $<0.01)$ & \\
positivity & & & \\
\hline
\end{tabular}

\section{CONCLUSION AND SUGGESTION}

This study result showed a significant correlation between IFN- $\gamma$ plasma levels with chest radiography $(r=0.365 ; \rho=0.029)$, and a significant correlation between IFN- $\gamma$ plasma level with sputum positivity ( $r=0.447 ; \rho=0.006)$. Results of level IFN- $\gamma$ between the severity level of the disease can be varied. It can be dependent on the interaction between the host cells, and CD+ 4 cells. These results showed that Th1 immune respons had a correlation with both lesion area, and sputum positivity. IFN- $\gamma$ plasma levels, and sputum positivity may reflect a Th-1immune response, so at the more severe level of disease, an immune response Th-1 became more activated. This study had limitations, so more research using intracellular cytokines or PBMC culture/Peripheral blood mononuclear cells with approximately 96 samples is needed. Radiography and sputum smear findings in this study depended on the interaction of the host immune response to pathogens that were not included in this study. 


\section{REFERENCES}

1. WHO. Global Tuberculosis Report. Switzerland, WHO press, 2013; 1-3.

2. Phillips AJ, Ernst DJ. Tuberculosis pathogenesis, and immunity. Annu. Rev. Pathol. Mech. Dis. 2012; 7(3): 53-84.

3. Rahman S. Local immune response in tuberculosis : Cytolytic effector function at the site of mycobacterium tuberculosis infection. Karolinska Institut. Stockhom 2013; 1-85.

4. Abbas KA. Cellular, and molecular immunology, Philadelphia,WB Saunders Company, Elsevier, 2012; 350 352.

5. Da silva M, Tiburcio GSM, Machado RJ, Silva AAD, Rodrigues RBD, Rodrigues V, Oliveira FJC. Complexity, and controversies over the cytokine profiles of $T$ helper cell subpopulations in tuberculosis. Hindawi publishing coorporation. Journal of Immunology Research, 2015;10: 1155-1170.

6. Tang J, Chen C, Zha C, Chang J.R, Fang Q, Wang ZH, Li BQ. Peripheral blood T cell TNF- $\alpha$, and IFN- $\gamma$ production stimulated by low molecular peptide of Mycobacterium tuberculosis heat-resistant antigen for differential diagnosis between pulmonary tuberculosis and latent tuberculosis infection. Journal of Southern Medical University 2017; 37(11):1442-1447.

7. Ebrahimzadeh A, Mohammadifard M, Naseh G. Comparison of chest $X$ ray findings of positive, and negative smear in patients with pulmonary tuberculosis. Iranian journal of radiology. 2014; 11(4): e13575.
8. van Dick $P$, van Hoenecker FM, van den Brande $P$ and de Schepper AM. Imaging of pulmonary tuberculosis. Abstract. Eur Radiol. 2003; 13(8): 1771-85.

9. Leung Ann N. Pulmonary Tuberculosis: The Essentials. Radiology 1999; 210: 307-322.

10. Lee Jae S, Kim Eui C, Joo Sei I, Lee Sang M, Yoo Chui G, Kim Yong $W$, et al. The Incidence and Clinical Implication of Sputum with Positive Acid-Fast Bacilli Smear but Negative in Mycobacterial Culture in a Tertiary Referral Hospital in South Korea. J Korean Med Sci 2008; 23(5): 767-71.

11. Nolan A, Fajardo E, Huie ML, Condos R, Pooran A, Dawson $\mathrm{R}$, et al. Increased Production of IL-4, and IL12 p40 from Bronchoalveolar Lavage Cells are Biomarkers of Mycobacterium tuberculosis in the Sputum.In Biomarkers of Tuberculosis Transmissibility. PLOS ONE. 2013; 8(3): e59461.

12. Instruction Manual ELISA kit. Download from www.ucytech.com. Diakses 15 Februari 2015.

13. National Tuberculosis Association of USA. Diagnostic standards, and classification of tuberculosis. New York, National Tuberculosis Association, 1961; 160-162.

14. Hussain S, Afzal N, Javaid K, Ullah IM, Ahmad T, Saleem-Uz. Level of Interferon Gamma in the Blood of Tuberculosis Patients. Iran J. Immunol. December 2010; 7(4): 240-246.

15. Saidu SA, Makusidi AM, Njoku CH. Chest Radiography findings in sputum smear positive pulmonary tuberculosis as seen in Usmanu Danfodiyo University teaching Hospital Sokoto, Nigeria. BOMJ. 2013; 10(1): 20-24. 